\title{
Flexibility in the Face of Change
}

\section{A Review of the Serials Literature, 2010-11}

\author{
Sarah W. Sutton
}

The serials literature for 2010-11 reflects the need for all members of the serials information chain to demonstrate flexibility in the face of constant change. Both the current economic context and the rapid development of technology are providing users with more options than ever before for fulfilling their information needs. The literature reflects this and the actions that members of the serials information chain are taking to evaluate, measure, and deliver serials content in new and creative ways. The major themes in the serials literature-workflows and processes, access to serials, metrics, and changing user behavior-are described and illustrated using examples from a selection of materials published during 2010-11.

Sarah W. Sutton (ssutton3@emporia.edu) is Assistant Professor, School of Library and Information Management, Emporia State University, Emporia, Kansas.

Submitted June 15, 2012; tentatively accepted July 14, 2012, pending modest revision; revisions submitted September 13,2012 , and accepted for publication.

The author gratefully acknowledges the assistance of Jack Boetcher and a grant from the Carnegie-Whitney Foundation and the Association for Library Collections and Technical Services, which made possible the creation of the review.
$\mathrm{T}$ he serials literature for 2010-11 reflects an evolution of the serials information chain that librarians on the front lines will immediately recognize. The serials information chain comprises "serials librarians, serials publishers, subscription agents, representatives of bibliographic utilities, and library science educators-in short, all parties interested in serials." Stringent economic conditions are forcing libraries to assess and reassess the value of every dollar spent on collections. The technologies through which libraries deliver the content of serials collections have advanced rapidly. The combination of these occurrences has created an atmosphere of change and evolution. Users are conveying their desire for content and content delivery through word and action, and every member of the serials information chain from librarians to publishers to vendors to agents are working in collaboration to understand these needs, to develop systems and processes to respond to them, to measure them, and to anticipate what they will be in the years to come.

The author compiled, selected, and analyzed the literature for this review using qualitative research methods with the assistance of a graduate research assistant (GRA). The author and the GRA identified an initial group of 419 articles published in the 2010 and 2011 volumes of three core serials journals: The Serials Librarian, Serials Review, and Serials. The author and the GRA used these sources to identify key words that they then used for a broader literature search in the databases Library, Information Science and Technology Abstracts with Full Text, and Library and Information Science Abstracts. The author and the GRA identified additional materials via citations to and within the initial article collection as well as from the archives of SERIALST, "an informal electronic 
forum for most aspects of serials processing in libraries." The final pool of documents contained 598 items. In addition to appearing in these sources, criteria for selection at this stage were broad, consisting of language (English) and publication date (2010 or 2011).

The author and the GRA read article abstracts and, in many cases, the articles themselves, making notes on content and suitability for inclusion in the review. The author loaded these citations, abstracts, and notes into NVivo 9 (a qualitative data analysis software) and read and annotated any unread items. She inserted her additional notes into NVivo 9, then reviewed the data again, this time for the purpose of identifying topical patterns and themes (NVivo calls them nodes). The author coded (i.e., identified with) each summary, abstract, and note at one or more thematic nodes. The author reviewed the resulting list of thematic nodes for content. She selected thematic nodes for inclusion in this literature review on the basis of a combination of coverage in the literature and relevance to members of the serials information chain. Finally, the author reviewed the material coded at each thematic node to further develop definitions of and ideas about the themes they represented. The breadth of the serials literature precludes the inclusion of all of the topical nodes in this review. Nodes that were excluded are journal content licensing and copyright, journal access content standards, serials selection, and open access.

Two overarching themes and four more specific themes emerged from the analysis and coding process. The overarching themes are the economic constraints facing libraries and their serials collections and the shift from print to online formats for the delivery of serial content. The overarching themes are prevalent enough in the literature to warrant separate discussion, although they are interwoven in all of the more specific themes. The four more specific themes are serials workflows and processes, access to serials content, metrics for decision support, and changing user behavior. Descriptions and discussion of these themes make up the rest of this review.

\section{Economic Constraints Facing Libraries and Their Serials Collections}

The discussion of decreasing budgets pervaded the literature in $2010-11$ as it has for years. ${ }^{3}$ The overarching theme of economic constraints in the current literature has the following facets:

- strategies for maintaining service during steep cuts to the serials budget and maximizing serials access

- the continuing transition to online formats

- institutional budget reorganization to increase available funds for serials
Zappen and Throumoulos recommend a strategy of combined activities. ${ }^{4}$ Those activities are collaborating with faculty before making decisions on cancelations or transition to new formats and presenting institutional administrators with data describing the affect of cuts. Zappen recommends "tracking the price inflation of serials, monitoring its impact on the materials budgets and library collections." She advocates valuing access over ownership when transitioning to online formats while Throumoulos suggests heavier reliance on document delivery (both interlibrary loan and pay-perview).

Strategies for freeing additional resources for serials and e-resources management as a reaction to economic constraints are wide ranging. Zappen reports that ceasing service as a federal documents repository has freed resources for other priorities. ${ }^{6}$ Busby points out that hidden costs, such as staff time and effort to process and maintain serials, must be weighed against the benefits of consortial purchases like lower subscription costs and shared negotiations. ${ }^{7}$ The serials world seems to be on the fence regarding both consortial and Big Deal purchases. Big Deal purchases are agreements between a publisher and a library or group of libraries under which the library agrees to pay a premium on the cost of their existing subscriptions (perhaps 10 or 15 percent) being provided with electronic access to all of the publisher's publications in return. Several of Powell's strategies reflect a move away from consortial purchase including renegotiating multiyear Big Deals or cancelling them and subscribing to journals individually. ${ }^{8}$ According to Powell, these types of decisions should be metrics-based (usage, faculty recommendations, historical price increases, and local ratings).

Additional strategies for dealing with economic constraints found in the literature include discontinuing the practice of "convenience" replication (e.g., course packs created from library owned materials), seeking open access (OA) content, consolidating subscription vendors, negotiating for lower fees, and consolidating access and management software services (e.g., link resolvers, A-to-Z journal lists, discovery, federated search, electronic resource management systems (ERMS)). Zappen, Powell, and Riggio, Tijerina, and Cook also recommend reducing duplication across formats. ${ }^{9}$

\section{Shift from Print to Online Formats for the Delivery of Serial Content}

Many of the articles representing the second overarching theme in the literature, the shift from print to online formats, discuss the causes of the shift. The impetus for the shift that is apparent in the current literature involves libraries' reaction to rapid technological change and the economic climate that has resulted in mandated budget cuts. The 
literature also reflects the obstacles and barriers that members of the serials information chain are facing and working creatively to overcome.

Henderson and Bosch identify one root cause of the shift when they note "the tightening economy has accelerated the already rapid move from print journals to online-only to widen access while containing cost." ${ }^{, 10}$ Spagnolo, Pennington, and Carter note other causes of the shift. ${ }^{11}$ The report that most libraries have reduced the number of their print subscriptions in favor of online subscriptions either as a reaction to changing patron need and desire or to reduce staffing resources required to process print. By reducing or eliminating check-in, claiming, binding, ceasing to place security strips in issues that will be bound, binding incomplete issues, ceasing comprehensive title-level invoice checking in favor of spot checking high risk and use titles, libraries save staff time and, in some cases, can redirect these savings to managing online resources. Spagnolo, Pennington, and Carter observe "decision-making [of this kind] is based as much as possible on physical criteria and anticipated use rather than past practice or tradition." 12

The shift to electronic formats has been incorporated into collection policies with reasonable exceptions that include faculty needs and desires for print and instances where the library has a heavy responsibility for archiving or preserving specific content. ${ }^{13}$ The shift is spurred by increasing reliability of stable archives (e.g., Portico and JSTOR) and sometimes involves Big Deal contracts for online journal content and the implementation of serials and access management tools such as link resolvers, discovery tools, and ERMs.

The other major theme is the obstacles and barriers to making the switch. Sullenger's case study of the Auburn University Libraries' serials format inventory project illustrates this well. ${ }^{14}$ She discusses the local constituents' desire to keep print format and the unacceptable (to the library) conditions placed on electronic access by publishers. These unacceptable conditions include publishers who make access to online content available to individuals but not to institutions, deliver online content via email, or limit access to online content to use on a dedicated terminal in the library or to a maximum number of simultaneous users. Other examples of unacceptable conditions include access to online content that can only be controlled by username and password (rather than providing authentication via IP address), the vendor's online interface is awkward to use, and the price for institutional subscriptions is too high.

Both the economic constraints under which libraries are operating and the shift from print to online content are reflected in the four topical themes that comprise the rest of this review. Workflows and processes are changing not only to meet users' desire for online content but also to improve efficiency and maximize shrinking budgets. Access to serials content online to meet user demand also has provided members of the serials information chain with opportunities for increasing efficiencies. Libraries are using metrics, such as usage statistics, to measure the effectiveness of funds spent and support decision making related to the shift from print to online. User behavior is both a reflection of rapid change and a driver of it.

\section{Serials Workflows and Processes}

Much of the literature related to the shift from print to online is coded at the workflows and processes thematic node, most likely because changing formats has spurred the need to change workflows and processes. Many of the articles coded at the shift from print to online node discuss the reasons for the shift, and those coded at the workflows and processes node discuss what to do about it.

Within the theme of workflows and processes, the most prominent topic is reaction to rapid change and a resulting emphasis on patron-focused services. Reduced budgets and rapidly changing technology have forced libraries to realize that they cannot be everything to all people but must focus on their primary local constituencies needs. Sometimes this has meant changing or even eliminating workflows and processes that are deemed of lower priority in meeting patron needs (for example, serials check-in). ${ }^{15}$ Blackburn and Lowden address this change when they say that libraries need to "focus their efforts on what their target audience specifically needs."

The literature contains discussions of how to change workflows, particularly with regard to serials management and developing new systems (both in terms of processes and software) that will accommodate rapid change and a move to greater patron focus. Chamberlain reports a comment on the duration of workflows made by an OCLC product analyst: "we are past the day where there is a workflow and that is how it needs to be done for the next ten years. I do not think we can guarantee that even for two years." ${ }^{, 17}$ Instead of developing systems and workflows to meet specific existing or even predicted needs, libraries should be designing systems and workflows with enough flexibility to accommodate rapidly changing serials management models.

Tbaishat presents a case study of two libraries' acquisitions workflows that focus on the use of role activity diagrams (a business-process modeling technique) to illustrate the differences between the two libraries (one in the United Kingdom and one in Jordan). ${ }^{18}$ This case study is particularly interesting because it suggests that libraries might benefit from adapting systems analysis and modeling techniques from other industries. The adaptation of techniques used in nonlibrary settings is an opportunity to continue along the path of maximizing resources. 
Another topic in the literature is the need for increased interoperability between software systems. One example is the development of the CUFTS reSearcher suite of tools done at Simon Fraser University and the University of Prince Edward Island and reported by Taylore, Dodd, and Murphy. ${ }^{19}$ Not only would increased interoperability increase the level of flexibility, it would also serve the goal of maximizing limited resources. Blackburn and Lowden report on research done by OCLC to understand "new user needs and how they might be combined into a single, integrated, serial and electronic product workflow." ${ }^{20}$ On the basis of this research, they recommend that acquisitions librarians "focus their efforts on what their target audience specifically needs." ${ }^{\text {"21 }}$ They make several recommendations for future development of serial acquisitions software. Serials acquisitions software needs to have "maximum interoperability with other systems within their libraries" and "flexibility to work within the library's current practices. ${ }^{.22}$ Libraries also need "a single place" to assess current and potential subscriptions at annual renewal time as well as a system that would allow them to "act on this evaluation." 3

The libraries (University of California-Davis, University of Missouri-Kansas City, and University of Alberta) described by Spagnolo, Pennington, and Carter have reorganized technical services (including serials) by centralizing processing in cases of multiple libraries, organizing units on the basis of function instead of format, and cross-training staff to handle multiple responsibilities. ${ }^{24}$ Centralized processing in this case took the form of a single acquisitions department that accomplished purchasing for all branch libraries. Cross-training "has provided us [the University of California at Davis within the University of California System] with an ability to maneuver in response to fluctuating needs and different cycles between monographs and serials." ${ }^{25}$ This reflects growing flexibility in the face of change on the libraries described.

It is noteworthy that the articles coded at the serials workflows and processes node, with one exception, deal with changes to library workflows and not workflows in other areas of the serial information chain. Fritsch and Lee offer the exception. ${ }^{26}$ These authors describe a new collaboration between the University of California Press (UCP) and JSTOR to make current nonprofit publishers' journal issues available on a stable, robust platform. This new collaboration is based on an existing relationship between JSTOR and UCP. JSTOR has hosted UCP's back files for many years. This collaboration has resulted in a system that both preserves scholarly journal content and delivers it to users. This approach relieves the mounting financial burdens of keeping pace with technological developments faced by small, nonprofit publishers and provides sales and customer service support to the UCP. Benefits to libraries include the use of exiting JSTOR licenses, which means that libraries that have a JSTOR license do not have to negotiate new licenses with each small press publisher. Libraries will have improved usage metrics that strengthen "a library's ability to gather usage statistics for evidence-based collection management." ${ }^{27}$ Digital preservation is another benefit for libraries. Benefits for journal users include strengthening the JSTOR platform as a discovery tool through the addition of current content, "seamless access to full runs of journals," reduced interface downtime, and the ability to keep pace with user needs by keeping pace "with changes in technology and pedagogy." ${ }^{28}$

Schonfeld reports on Ithaka's project to develop a "What to Withdraw Framework," a decision support tool for libraries to use when deciding to cancel or withdraw print collections in favor of online versions of scholarly journals. ${ }^{29}$ Ithaka based this tool on the results of their 2009 faculty survey, which indicated that increasing numbers of faculty in all disciplines have become comfortable with relying on local journal collections in electronic formats. However, Housewright, in reported on the 2009 faculty survey, noted that faculty ranked the role of the library as an archive of important materials as the second most important of five roles, implying that faculty still views one of the roles of the library to be preservation of the scholarly record. ${ }^{30}$

\section{Subscription Management}

A challenge faced in subscription management is changing workflows and processes. The literature reflects two primary themes: providing consistent access and the need for libraries, publishers, and subscription agents to agree on holdings at the journal title level, and the actual acquisitions process.

Blake and Collins present a thorough analysis of the issues related to the need for libraries, publishers, and subscription agents to agree on holdings at the journal title level to provide consistent access. ${ }^{31}$ They describe several solutions in use at academic libraries: EBSCO's Rapid Renewal Tool, publisher's electronic holdings reports, Web 2.0 tools to document individual institution's management decisions, and data from a proprietary knowledge base (e.g., SFX). Blake and Collins also present three approaches to manage e-holdings used by the librarians they interviewed: highly managed, service-reliant management, and combined approaches. The highly managed approach consists of activating, testing access, and verifying holdings for each individual journal title one by one. The advantage of this approach is a high rate of accuracy in holdings displays. The disadvantage is the large amount of time it requires. The service-reliant approach consists of accepting the holdings information supplied by vendors via the library's link resolver knowledge base. The advantage of this approach is time-savings, which allows libraries to make holdings available to their patrons more quickly. The disadvantages 
are occasional discrepancies between the holdings identified in a library's contract with a publisher and the holdings displayed in the knowledge base. The combined approach involves taking the highly managed approach for unique collections while taking the service-reliant approach for managing package title lists. The authors conclude with trends they see in e-holdings management: an increase in tools used to manage e-holdings and a continued need for interoperability between systems.

The second theme, changes to acquisitions processes, is represented in two articles from Europe. Tjensvoll writes about the benefits of the acquisitions process (a form of the Big Deal) used by the Norwegian Electronic Health Library. ${ }^{32} \mathrm{He}$ extols the advantages to citizens of Norway of a bid-based purchasing model for materials added to the Norwegian Electronic Health Library, specifically, the public availability of BMJ Best Practice and UpToDate, which resulted from use of the model. Best Practice and UpToDate are research databases designed to deliver evidence-based research to healthcare professionals in their workplace via mobile devices. ${ }^{33}$ Earney offers a partial response to and personal reflection on Tjensvoll's article. ${ }^{34}$ Earney questions whether a call for bids is an appropriate way to license unique electronic resources and suggests that direct negotiations between vendor and subscriber would result in greater cost savings to the public.

\section{Integrated Library Systems and Open-Source Software}

A relationship exists between integrated library system (ILS) and subscription management workflows. Although not covered in previous serials literature reviews, the use of the ILS as both a means of managing subscriptions and providing access to serials was a strong enough theme in the 2010-11 serials literature to warrant mention. The articles coded at the ILS and open-source software thematic node (see appendix) suggest that libraries are looking for a system that will provide a single format-neutral place to efficiently gather, store, and analyze all the data related to serials management, and allow using that same data to improve access to serials. The ILS has the potential (although not yet realized) to serve this purpose.

The ILS also is a topic of interest in relation to the move libraries are making toward integrating print and online holdings data into a single source. Many libraries are turning to open-source ILS software for a solution. For instance, Liu and Zheng report success with a project at the University of Windsor Leddy Library to combine the display of their print and online holdings by integrating data from their open-source ILS, Evergreen ${ }^{35}$ Blackburn and Lowden report on research done by OCLC "to understand ... new user needs and how they might be combined into a single, integrated, serial and electronic product workflow. ${ }^{36}$
Based on this research, they recommend that acquisitions librarians "focus their efforts on what their target audience specifically needs. ${ }^{37}$ They make several recommendations for serial acquisitions software. It needs to have "maximum interoperability with other systems within their libraries" and "flexibility to work within the library's current practices." ${ }^{38}$ Libraries also need "a single place" to assess current and potential subscriptions at annual renewal time as well as a system that would allow them to "act on their evaluation."39

The use of open-source software is one means of facilitating access to both print and online serials because, as Liu and Sheng report, integrating print journal holdings data from an open-source ILS with data from an OpenURL link resolver can create a comprehensive, format-agnostic A-to-Z list of a library's journals holdings. ${ }^{40}$ Taylor, Dodd, and Murphy describe the collaborative creation of an opensource ERMS. ${ }^{41}$ Johnson offers the opinion that interest and work on open-source ILS will increase. ${ }^{42}$ Chad portrays the benefits and disadvantages of open source. ${ }^{43}$ The benefits, according to Chad, include making data more widely available that will, in turn, enhance and encourage innovation, return control of the system of scholarly communications to the scholars, and support software development that meets the needs of higher education. Chad identifies the greatest challenge of open source as creating applications that have a broad appeal in terms of reusability. Another perspective on open source is offered in a report of a panel discussion between the executive director of Kuali OLE (an open library environment), a project analyst at OCLC, and a senior project manager with Innovative Interfaces, held at the 2010 annual meeting of the NASIG. ${ }^{44}$ One topic of their discussion was the integration of open-source serials management tools and ILSs.

\section{Access to Serials Content}

Thematic issues related to access to serials (derived from the references coded at "access to serials") include the need for increased and improved communication between members of the serials information chain, the increasing use of diverse platforms for content access, the changing behavior of users, how those changes are the impetus for changes in delivery platforms and interface design, and the provision of access points through the use of metadata.

A lack of communication between publishers, subscription agents, and libraries results in a loss of access to e-journals at renewal time, loss of back files (when the publisher changes their business or access model), and lack of knowledge of "what period of access we are supposed to have for each of our electronic titles." ${ }^{\text {" }} 5$ Pearson and Box suggest that publishers should "not only collaborate with libraries to drive usage but to share the data that they collect 
such as usage half-life and path analysis." ${ }^{" 46}$

The delivery of journal content to mobile devices is the topic of growing number articles. Many deal with how libraries might best accomplish delivery of content to mobile devices and some relate to "shifting patterns of media consumption." ${ }^{37}$ White, Anderson and Dresselhaus, and Evans all suggest that to accomplish delivery of journal content to mobile devices, libraries and publishers must work together to understand the expectations of users for mobile journal content access. ${ }^{48}$ Picco, Cohn, and Rosenblatt of Atypon, "a leading provider of software to the professional and scholarly publishing industry" and publisher of the Literatum platform, report on a project begun in 2010 to deliver content to mobile devices. ${ }^{49}$ The report suggests three strategies for the delivery of content to mobile devices: first, ensuring that delivery is available to all types of mobile devices; second, providing support for authentication; and third, limiting the density of content per page because screens are smaller and dense information on touchscreens is particularly difficult to navigate. Sheail observes that, for students in online-only learning environments, the library is equivalent to its web interfaces, both mobile and otherwise, and predicts a continued shift toward the consumption of electronic journal content. ${ }^{50}$

Related to the growing use of mobile devices to access journal content among library patrons is the topic of user search behavior. The use of mobile devices represents one of several new behaviors that are being taken into account in the design of access points for e-serials. In his 2010 paper describing a serials cancellation project, Matlak suggests that the way in which users are browsing and using the web for their research is defining what kind of research they are using. ${ }^{51}$ Article database usability studies support this conclusion. Fry reports the results of a usability study of college undergraduate students that determined that students tend to use web-based search interfaces with which they are familiar. ${ }^{52}$ The literature includes some discussion of web and interface design and the incorporation of Web 2.0 tools to deliver journal content to users. One aspect of this is the use of mash-ups to create new services and applications. ${ }^{53}$ Beccaria, Tennant, and Traub describe OCLC's xISSN web service, an application program interface (API), enables libraries to retrieve serials metadata from WorldCat in parsable form that, in turn, allows libraries to enhance their local catalogs by combining the metadata with local holdings information. ${ }^{54}$ Lie and Zheng describe how libraries are beginning to present users with a single multiformat serials display. ${ }^{55}$ Matlak notes that multiformat serials displays have the advantage of providing easy access to print and electronic journals and increasing journal usage ${ }^{56}$ Wisniewski suggests that multiformat displays have the potential to present users with a single search box that searches the entire print and electronic collections. ${ }^{57}$
Mercer and Dyas-Correia point to the central importance of metadata to the scholarly communication lifecycle, of which serials access is an integral part. ${ }^{58}$ In their article, the authors present "a case for finding global solutions to improve the metadata that are available for journals, particularly small, independent, open-access journals. ${ }^{י 59}$ They provide examples of the importance of metadata to the discovery, access, and use of publications and offer suggestions for how librarians can partner with editors and publishers to enhance discoverability and usability for patrons. For instance, the authors suggest that librarians can take an increased role in publishing by creating repositories, educate editors and publishers on how to obtain ISSNs and Digital Object Identifiers (DOIs), assist journal publishers to understand the implications of title and format changes, and help editors and authors understand OA policies.

Although the implementation of Resource Description and Access: RDA for serials cataloging was discussed in the serials literature, the author found little evidence during the review period of its adoption or of the consequences for users. ${ }^{60}$ Two conference presentations on serials cataloging at the 2010 annual NASIG meeting discuss new MARC coding developments and a report on further testing of $R D A$. Hawkins, Nguyen, and Tarango introduce the 588 MARC field (Source of description note), which was introduced to support CONSER testing of RDA. ${ }^{61}$ El-Sherbini describes the changes serials catalogers will face with the implementation of $R D A$ including the elimination of abbreviations and the identification of relationships between manifestations of a single work and additional descriptive MARC fields (336 (Content type), 337 (Media type), and 338 (Carrier type)) for electronic journals. ${ }^{62}$

Several researchers studied the way libraries are making OA publications available to their patrons. Collins and Walters look at how liberal arts colleges make use of OA journals on the assumption that "students and scholars can take full advantage of OA journals only if libraries make them available through mechanisms that are familiar to patrons." ${ }^{\prime 63}$ Publishers and interface vendors appear to have taken this to heart. Looking for alternative income streams, large publishers "continue to cherry-pick the most successful OA journals and add them to their packages (at a price)." ${ }^{.64}$

\section{Metrics and Decision Support}

The literature reflects the need for reliable usage data and other metrics. This likely stems from the ongoing need to inform cancellation projects. Several articles report on the creation of decision support systems (DSS) created to compile data relevant to actions (e.g., acquisition and cancellation) related to serials subscriptions. Nixon describes a homegrown decision support system created by the Purdue 
University Libraries that allowed librarians to gather and manipulate together data from a variety of disparate sources including their ILS, their link resolver, and the Institute for Scientific Information (ISI). ${ }^{65}$ The reports produced by their system allowed them to identify specific criteria that they would share with faculty members to build consensus for subscription cancellations. Carroll and Cummings describe a similar system that was developed at Washington State University (WSU) and integrated data from an ILS, an ERMS, Project COUNTER, subscription agent knowledge bases, interlibrary loan software, and citation databases-all of which were loaded into an Excel spreadsheet. ${ }^{66}$ The WSU DSS is used not only to support cancellation decisions but also to support journal selection and analysis of vendor and aggregator package agreements.

Most articles coded at the metrics and decision support node identify the need to create and use usage data and DSSs, which are often necessary to respond to mandates placed on libraries by the institutions that they serve to either provide data that describe the return on investment for the dollars spent by the institution or in response to calls for budget cuts or both. Some authors question the concept of use that underlies the drive to quantify and measure journal use. Fleming-May suggests that "the concept of 'use,' however, is complex and must be fully understood for meaningful incorporation into assessment measures." ${ }^{" 67}$ Matlak suggests that "usage is being driven by the style of research that the Internet encourages. ${ }^{\prime 68}$ Pearson and Box suggest that the context in which usage data are obtained, e.g., "the path taken by users to obtain journal articles," could inform collection development decisions. ${ }^{69}$ Henderson and Bosch note that

when use becomes a key part of the value proposition, it can lead to commoditization of library resources. Content that is used is "good" irrespective of [its] quality. Much of the content in the scholarly and cultural record may not appeal to popular tastes or merely reflects the current hot topics in scholarly discourse. Libraries will have to make hard decisions to meet current user demands and to preserve quality information that doesn't see significant use in the short term. ${ }^{70}$

\section{Changing User Behavior}

An interesting theme in the serials literature examines the results that changing user behavior is having on the collection of and provision of access to serials. Matlak starts with the premise that usage statistics are the benchmark for deciding how to manage collections. ${ }^{71} \mathrm{He}$ then argues that usage statistics lack context because they describe what is being used but do not reveal what drives usage. He concludes that what drives usage is user search behavior.
The way in which users are browsing defines what kind of research they are using rather than the quality of an article, that is, they use what is visible and convenient. White suggests that, as mobile devices become "the default access devise to a work of information and applications" and that "understanding the expectations of these users will be of paramount importance in providing profitable value added services." ${ }^{, 72}$ Picco, Cohn, and Rosenblatt also suggest that mobile technology is becoming the access device of choice for researchers and scholars. ${ }^{73}$

Another perspective is presented by Fry who analyzes what libraries can do to help users access their databases by enhancing their utility for patrons and thereby increase use. ${ }^{74}$ Fry's suggestions include recommending new databases to students that share a common interface with databases with which students are familiar, asking proprietary ERMS vendors to provide flexibility that allows libraries to create student-friendly discovery pages, and making use of web-scale discovery systems. Padley presents HTML5 (the fifth edition of HyperText Markup Language) as a solution to the problem of publishers' needing to support multiple platforms for delivery of content to mobile devices. ${ }^{75}$ Rapple reports on Annual Reviews' experience developing a strategy for making its journal content accessible via mobile devices. ${ }^{76}$ Evans suggests that the move to mobile devices for scholarly content exploration is a shift in the pattern of media consumption. ${ }^{77}$

The literature reviewed in this section suggests that usage is driven by shifting patterns of media consumption (e.g., the mobile device now, possible something else later) and that part of that shift is away from judgments of quality in media consumption and toward user convenience. Henderson and Bosch say "when use becomes a key part of the value proposition, it can lead to commoditization of library resources. Content that is used is 'good' irrespective of quality. Libraries will have to make hard decisions both to meet current user demands and to preserve the quality information that doesn't see significant use in the short term. ${ }^{.78}$

\section{Conclusion}

The key themes that emerge from the 2010-11 serials literature are economic stringency; an increasing shift from print to online formats; workflows and process that address the transition from print to online, subscription management, and integrated library systems that facilitate serials work; access to serials content; metrics for decision making; and changing user behavior. These themes reflect the need for flexible solutions to the challenges of the current information society and those that are to come.

The bottom line is that libraries can no longer afford to be all things to all patrons. Limited resources require 
libraries to prioritize what they do by creating workflows that focus their work on providing the materials and content that are most needed and desired by their specific patron base and by creating workflows flexible enough to change as those needs and desires change.

\section{References}

1. Leigh Chatterton and Mary Elizabeth Clack, introduction to The Serials Information Chain: Discussion, Debate, and Dialog: Proceedings of the North American Serials Interest Group 2nd Annual Conference June 14-17, 1987, Denison University, Granville, Ohio (New York: Haworth, 1988): 1.

2. "SERIALST Scope and Purpose: Including Fileserver Information and Selected Command Options," SERIALST (Serials in Libraries Discussion Forum), accessed August 31, 2012, www.uvm.edu/ bmaclenn/serialst.html.

3. Patrick L. Carr, "From Innovation to Transformation: A Review of the 2006-7 Serials Literature," Library Resources \& Technical Services 53, no. 1 (January 2009): 3-14; Maria Collins, "Serials Literature Review 2008-9: Embracing a Culture of Openness," Library Resources \& Technical Services 55, no. 2 (April 2011): 60-80.

4. Susan H. Zappen, "Managing Resources to Maximize Serials Access: The Case of the Small Liberal Arts College Library," Serials Librarian 59, no. 3/4 (2010): 346-59; Mary K. Throumoulos, "Exceptional Service During and After Deep Serial Cuts," Bottom Line: Managing Library Finances 23, no. 1 (2010): 24-28.

5. Zappen, "Managing Resources to Maximize Serials Access," 349.

6. Zappen, "Managing Resources to Maximize Serials Access."

7. Lorraine Busby, "Our Friends Are Killing Us," Serials Librarian 61, no. 2 (2011): 160-67.

8. Allen Powell, "Times of Crisis Accelerate Inevitable Change," Journal of Library Administration 51, no. 1 (2011): 105-29.

9. Zappen, "Managing Resources to Maximize Serials Access"; Powell, "Times of Crisis Accelerate Inevitable Change"; Angela Riggio, Bonnie Tijerina, and Eleanor I. Cook, "Don't Pay Twice! Leveraging Licenses to Lower Student Costs," Serials Librarian 60, no. 1/4 (2011): 153-57.

10. Kittie S. Henderson and Stephen Bosch, "Seeking the New Normal," Library Journal 135, no. 7 (April 15, 2010): 37.

11. Lisa Spagnolo, Buddy Pennington, and Kathy Carter, "Serials Management Transitions in Turbulent Times," Serials Review 36 , no. 3 (2010): 161-66.

12. Ibid., 162.

13. Spagnolo, Pennington, and Carter, "Serials Management Transitions in Turbulent Times."

14. Paula Sullenger, "A Serials Format Inventory Project: How Far Can Academic Libraries Go with 'Electronic Only?? Serials Review 37, no. 3 (2011): 176.

15. Lisa Pate, "Check in/Maintain/Catalog Serials," SERIALST,
April 25, 2011, http://list.uvm.edu/cgi-bin/wa?A2=ind1104\& $\mathrm{L}=$ serialst $\& \mathrm{D}=0 \& \mathrm{~T}=0 \& \mathrm{P}=41178$.

16. Jonathan Blackburn and Sylvia A. Lowden, "Not for the Faint of Heart! A New Approach to Serials Management," Serials Librarian 60, no. 1/4 (January 2011): 72.

17. Clint Chamberlain et al., "Serials Management in the NextGeneration Library Environment," Serials Librarian 60, no. 1-4 (January 2011): 38.

18. Dina Tbaishat, "Using Business Process Modeling to Examine Academic Library Activities for Periodicals," Library Management 31, no. 7 (November 2010): 480-93.

19. Donald Taylor, Frances Dodd, and James Murphy, "OpenSource Electronic Resource Management System: A Collaborative Implementation," Serials Librarian 58, no. 1/4 (June 2010): 61-72.

20. Jonathan Blackburn and Sylvia A Lowden, "Not for the Faint of Heart! A New Approach to Serials Management," Serials Librarian 60, no. 1/4 (2011): 61.

21. Ibid., 72 .

22. Ibid., 73 .

23. Ibid.

24. Spagnolo, Pennington, and Carter, "Serials Management Transitions in Turbulent Times."

25. Ibid., 162.

26. David R. Fritsch and Rachel Lee, "It's Time to Join Forces: New Approaches and Models That Support Sustainable Scholarship," Serials Librarian 60, no. 1/4 (2011): 75-82.

27. Ibid., 79 .

28. Ibid., 79-80.

29. Roger C. Schonfeld, "What to Withdraw? Print Collection Management in the Wake of Digitization," Serials Librarian 60, no. 1/4 (January 2011): 141-45.

30. Laurel Ivy Sammond, recorder, and Ross Housewright, presenter, "Print Collections Management in the Wake of Digitization," Serials Librarian 61, no. 2 (September 2011): 19395.

31. Kristen Blake and Maria Collins, "Controlling Chaos: Management of Electronic Journal Holdings in an Academic Library Environment," Serials Review 36, no. 4 (December 2010): 242-50.

32. Kjell Tjensvoll, "National Licensing for the Norwegian Electronic Health Library," Serials 24, no. 1 (2011): 52-55.

33. "About Best Practice," BMJ Group, accessed September 19, 2012, http://bestpractice.bmj.com/best-practice/marketing/about-best-practice.html; UpToDate homepage, accessed September 19, 2012, www.uptodate.com/index.

34. Liam Earney, "On the Advantages of Negotiation: A Partial Response to Kjell Tjensvoll,” Serials 24, no. 3 (2011): 273-76.

35. Guoying Liu and Huoxin Zheng, "Access to Serials: Integrating SFX with Evergreen Open Source ILS," Library Hi Tech 29, no. 1 (August 3, 2011): 137-48.

36. Blackburn and Lowden, "Not for the Faint of Heart!" 61.

37. Ibid., 72 . 
38. Ibid., 73 .

39. Ibid.

40. Liu and Zheng, "Access to Serials."

41. Taylor, Dodd, and Murphy, "Open-Source Electronic Resource Management System.”

42. Kay G. Johnson, "Reflections on Changes in the Library and Serials Literature," Serials Review 36, no. 4 (December 2010): 240-41.

43. Ken Chad, "Open Library Environments," Serials 24, no. 3 (November 2011): 216-19.

44. Chamberlain et al., "Serials Management in the Next-Generation Library Environment."

45. Jeanette Skwor, "Confirming E-Access Dates," SERIALST, Nov. 2, 2010, http://list.uvm.edu/cgi-bin/wa?A2=ind1011\&L $=$ SERIALST $\& \mathrm{P}=\mathrm{R} 1258 \& \mathrm{D}=0 \& \mathrm{~T}=0$.

46. Sarah Pearson and Christian Box, "Driving Usage-What Are Publishers and Librarians Doing to Evaluate and Promote Usage?” Serials 24, no. 3 (November 2011): 231.

47. Baker Evans, "The Ubiquity of Mobile Devices in Universities-Usage and Expectations," Serials 24, supplement 3 (November 2011): S11.

48. Martin White, "A World of Learning in the Palm of Your Hand," Serials 24, supplement 3 (November 2011): S65S70; Kent Anderson and Angela Dresselhaus, "Publishing 2.0: How the Internet Changes Publications in Society," Serials Librarian 60, no. 1/4 (January 2011): 23-36; Evans, "The Ubiquity of Mobile Devices in Universities."

49. Marty Picco, Kevin Cohn, and Bill Rosenblatt, "Any Time, Anywhere: Strategies for Mobile Content Delivery," Serials 24, supplement 3 (November 2011): S43.

50. Philippa Sheail, “Real Challenges in a Virtual World' or 'Can I Get Full Text from ERIC and What on Earth Is Dialog Datastar?'” Serials 23, no. 2 (January 1, 2010): 103-8.

51. Jeff Matlak, "What Drives Usage," Journal of Electronic Resources Librarianship 22, no. 3/4 (December 2010): 14465.

52. Amy Fry, presenter, and Marcella Lesher, recorder, "Beyond Lists and Guides: Using Usability to Help Students Get the Most Out of E-Resources," Serials Librarian 60, no. 1/4 (January 2011): 206-12.

53. Owen Stephens, "Mashups and Open Data in Libraries," Serials 24, no. 3 (November 1, 2011): 245-50.

54. Mike Beccaria, Roy Tennant, and Adam Traub, presenters; Sion Romaine, recorder, "Can't We Write a Little Script for This? Managing Serials Data and xISSN," Serials Librarian 60, no. 1/4 (2011): 181-85.

55. Liu and Zheng, "Access to Serials."

56. Matlak, "What Drives Usage."

57. Jeff Wisniewski, "Web Scale Discovery: The Future's So Bright, I Gotta Wear Shades," Online 34, no. 4 (2010): 55-58.
58. Holly Mercer and Sharon Dyas-Correia, "Metadata Value Chain for Open-Access E-journals," Serials Librarian 60, no. 1/4 (January 2011): 234-40.

59. Ibid., 234 .

60. RDA: Resource Description and Access (Chicago: ALA; Ottawa: Canadian Library Association; London: Chartered Institute of Library and Information Professionals, 2010).

61. Les Hawkins, Hien Nguyen, and Adolfo R. Tarango, "CONSER Update," Serials Librarian 60, no. 1/4 (2011): 124-34.

62. Magda El-Sherbini, presenter; Megan Curran, recorder, "Resource Description and Access 'RDA': New Code for Cataloging," Serials Librarian 60, no. 1/4 (2011): 7-15

63. Cheryl S. Collins and William H. Walters, "Open Access Journals in College Library Collections," Serials Librarian 59, no. 2 (September 2010): 195.

64. Stephen Bosch, Kittie Henderson, and Heather Klusendorf, "Periodicals Price Survey 2011: Under Pressure, Times Are Changing," Library Journal (April 14, 2011), accessed September 10, 2012, www.libraryjournal.com/lj/newsletters newsletterbucketacademicnewswire/890009-440/periodicals_ price_survey_2011_under.html.csp.

65. Judith M. Nixon, "A Reprise, or Round Three: Using a Database Management Program as a Decision-Support System for the Cancellation of Serials," Serials Librarian 59, no. 3/4 (2010): 302-12.

66. Diane Carroll and Joel Cummings, "Data Driven Collection Assessment Using a Serial Decision Database," Serials Review 36, no. 4 (December 2010): 227-39.

67. Rachel Fleming-May, presenter, and Amanda N. Price, reporter, "Downloads or Outcomes?: Measuring and Communicating the Contributions of Library Resources to Faculty and Student Success," Serials Librarian 61, no. 2 (2011): 197.

68. Matlak, "What Drives Usage," 147.

69. Pearson and Box, "Driving Usage-What Are Publishers and Librarians Doing to Evaluate and Promote Usage?” 226.

70. Kittie S. Henderson and Stephen Bosch, "Seeking the New Normal," Library Journal 135, no. 7 (April 15, 2010): 39.

71. Matlak, "What Drives Usage."

72. White, "A World of Learning in the Palm of Your Hand," S65.

73. Picco, Cohn, and Rosenblatt, "Any Time, Anywhere."

74. Fry, "Beyond Lists and Guides."

75. Richard Padley, "HTML5_-Bridging the Mobile Platform Gap: Mobile Technologies in Scholarly Communication," Serials 24, supplement 3 (November 2011): S32-S39.

76. Charlie Rapple, "The Mobile World: One Non-Profit Publisher's Journey," Serials 24, supplement 3 (November 2011): S57-S64.

77. Evans, "The Ubiquity of Mobile Devices in UniversitiesUsage and Expectations."

78. Henderson and Bosch, "Seeking the New Normal," 39. 


\section{Appendix. List of Themes}

\begin{tabular}{|c|c|}
\hline Theme & Subtheme \\
\hline \multicolumn{2}{|l|}{ Access vs. ownership } \\
\hline Access to serials & Authentication \\
\hline \multicolumn{2}{|l|}{ Aggregations } \\
\hline Assessing journal value & Usage stats \\
\hline \multicolumn{2}{|l|}{ Big Deal } \\
\hline \multicolumn{2}{|c|}{ Budgets—see Economic constraints } \\
\hline \multicolumn{2}{|c|}{ Cancellation projects } \\
\hline Cataloging & Metadata \\
\hline \multicolumn{2}{|l|}{ Change } \\
\hline \multicolumn{2}{|c|}{ Check-in and checking online access } \\
\hline \multicolumn{2}{|c|}{ Closed stacks } \\
\hline \multicolumn{2}{|l|}{ Cloud computing } \\
\hline \multicolumn{2}{|l|}{ Collection development } \\
\hline \multicolumn{2}{|l|}{ Consortia } \\
\hline \multicolumn{2}{|l|}{ E-books } \\
\hline \multicolumn{2}{|l|}{ Economic constraints } \\
\hline \multicolumn{2}{|l|}{ Globalization } \\
\hline \multicolumn{2}{|l|}{ Integrated Library Systems } \\
\hline \multicolumn{2}{|l|}{ Interoperability } \\
\hline \multicolumn{2}{|l|}{ Licensing } \\
\hline \multicolumn{2}{|l|}{ Link resolvers } \\
\hline Management tools & ERM; Excel; Mash ups \\
\hline \multicolumn{2}{|l|}{ Metrics } \\
\hline \multicolumn{2}{|l|}{ Open Access } \\
\hline \multicolumn{2}{|l|}{ Open-source software } \\
\hline \multicolumn{2}{|l|}{ OpenURL } \\
\hline \multicolumn{2}{|l|}{ Outsourcing } \\
\hline Perpetual access & \\
\hline Predictions for the future & \\
\hline Preservation & \\
\hline Programming (computer) & \\
\hline Publishers & \\
\hline Publishing models & \\
\hline Results of rising prices & \\
\hline Return on Investment & \\
\hline Role of the library & \\
\hline Scholarship and scholarly c & \\
\hline Serials pricing & \\
\hline Shift from print to online & \\
\hline Shifting patterns of media & \\
\hline Standards & \\
\hline Subscription agents & \\
\hline Subscriptions and renewals & \\
\hline training & \\
\hline User needs & \\
\hline User search behavior & \\
\hline Web-scale discovery & \\
\hline Work devoted to current $\mathrm{p}$ & \\
\hline Work flows and processes & Check-in and checking access \\
\hline
\end{tabular}

